\title{
Preconcentration and Sensitive Methodology for the Determination of Cadmium in Environmental Waters Using Dispersive Liquid-Liquid Microextraction Prior to Analysis by Atomic Fluorescence Spectrometry
}

\author{
Qingxiang Zhou ${ }^{\mathrm{a}, \mathrm{b} *}, \mathrm{Na} \mathrm{Zhao}^{\mathrm{b}}$, and Junping Xiao ${ }^{\mathrm{c}}$ \\ ${ }^{a}$ School of Chemistry and Environmental Sciences, Henan Normal University, \\ Henan Key Laboratory for Environmental Pollution Control, \\ Key Laboratory for Yellow River and Huaihe River Water Environment and Pollution Control, \\ Ministry of Education, Xinxiang 453007 , P.R. China \\ b State Laboratory of Petroeum Resource and Prospecting, College of Geosciences, \\ China University of Petroleum Beijing, Beijing 102249, P.R. China \\ ${ }^{c}$ Department of Chemistry, University of Science and Technology Beijing, Beijing 100083, P.R. China
}

\section{INTRODUCTION}

Cadmium is well known as a highly toxic element to humans and the environment. It is a ubiquitous and biologically non-essential element and is also classified as a borderline element. By accumulation in the body, cadmium may induce dysfunction and reproductive deficiencies (1), can damage organs such as kidneys, liver and lungs, and cause high blood pressure and destruction of red blood cells (2). Experimental and epidemiological studies have provided substantial evidence that low levels of long-term exposure to cadmium can contribute to increased risk of cancer. The maximum contaminant level (MCL) allowed by the American Environmental Protection Agency (U.S. EPA) in standard drinking water is $5 \mu \mathrm{g} \mathrm{L}^{-1}$ for ample protection to human health (3). The World Health Organization (WHO) established the maximum permissible level for cadmium as $3 \mu \mathrm{g} \mathrm{L}^{-1}$ in drinking water (4). Hence, sensitive and reliable analytical methods for the determination of cadium are of great importance.

Up to now, cadmium has been successfully determined by many different techniques: Flame atomic absorption spectrometry (FAAS) (5-6), electrothermal vaporization

\footnotetext{
*Corressponding autbor:

E-mail: zbouqx@cup.edu.cn,

zbouqx@benannu.edu.cn

Tel.: +8610-89733422

Fax: +8610-89733422
}

\section{ABSTRACT}

This paper describes a rapid and sensitive analytical method for the determination of $\mathrm{Cd}$ in water samples using dispersive liquid-liquid microextraction prior to analysis with atomic fluorescence spectrometry. In this experiment, 8-hydroxyquinoline was used as the chelating agent. Carbon tetrachloride and acetonitrile were used as the extraction and dispersive solvent, respectively. In the preconcentration process, the Cd complex was transferred into the carbon tetrachloride micro-droplets. After centrifugation, the carbon tetrachloride micro-droplets containing the Cd complex settled to the bottom of the centrifuge tube. Important factors that would affect the extraction efficiency were investigated including sample $\mathrm{pH}$, the amount of chelating agent, extraction time, and centrifugation time. The effect of coexisting ions in water samples was investigated and the results showed that no obvious negative effect was found. The experimental results indicated that the proposed method had a good linear range of $1-40 \mathrm{ng} \mathrm{mL}^{-1}\left(\mathrm{r}^{2}=0.9993\right)$. The precision was $1.93 \%$ (RSD, $\mathrm{n}=7$ ) and the detection limit was $19.4 \mathrm{ng} \mathrm{L}^{-1}$. The proposed method was validated with four real environmental samples and the recoveries were in the range of 81.9-104.0\%. All results indicated that the proposed method was excellent for future use.
(ETV)-ICP-MS (7), inductively coupled plasma mass spectrometry (ICP-MS) (8), electrothermal atomic absorption spectrometry (ETAAS) (9-12), graphite furnace atomic absorption spectrometry (GFAAS) (13), inductively coupled plasma atomic emission spectrometry (ICPAES) (14), and anodic stripping voltammetry (15). For many years, electrothermal and graphite furnace atomic absorption spectrometry have often been used for the determination of cadmium in various matrices owing to the wide application range, simplicity in operation, and low cost of analysis.

However, new techniques have been developed and achieved much more attention. They have been successfully used in the analysis of cadmium in many natural water samples. Atomic fluorescence spectrometry (AFS) is a relatively new and sensitive method for elemental analysis and has been successfully used for the determination of selenium, zinc, arsenic (16-17) and cadmium (18). Atomic fluorescence spectrometry was favored because it offers simplicity, ease of operation, low cost, and high sensitivity. Moreover, the concentration of cadmium in natural waters is often very low and has a very complex matrix. Hence, a preliminary separation and preconcentration step is often required. Flow injection for on-line column preconcentration of metal ions is an interesting 
alternative to the enrichment of cadmium (19). This system is generally less expensive, eliminates some interference effects, and achieves comparable parameters. In addition, this method offers favorable features such as high sample throughput and enrichment efficiency, low sample and reagent consumption, high reproducibility, low risk of contamination, and simple automated operation (20). Solid-phase extraction (SPE) is a popular sample pretreatment methodology and has been successfully used to develop good determination methods for cadmium (21-22). Meanwhile, solid phase extraction using imprinted polymer sorbents coupled to a flow injection system was reported to provide a more sensitive determination method for cadmium (23). Other preconcentration methods include single-drop microextraction (7), hollow fiber supported liquid membrane extraction (12), cloud point extraction (24), and solid phase extraction using sulfur powder modified with 2-mercaptobenzothiazole in the medium of 1-butyl-3-methylimidazolium hexafluorophosphate ionic liquid as the sorbent (25).

Recently, dispersive liquid-liquid microextraction (DLLME) has attracted increasing attention for its simple operation, rapidity, and high extraction efficiency. In this extraction procedure, two organic solvents with different characteristics are involved. One is the hydrophilicity which acts as a dispersive solvent such as ethanol, acetonitrile methanol, and acetone (26-27); the other acts as extraction solvent such as chlorobenzene and carbon tetrachloride (28-29). The extraction solvent forms innumerable small droplets when it is rapidly injected into the sample solution. These droplets limitlessly enlarge the contact area between extraction solvent and analytes. This method has been successfully utilized for the determination of heavy metals, polychorinated biphenyls (PCBs), polycyclic aromatic hydrocarbons (PAHs), polybrominated diphenyl ethers (PBDEs), pesticides and herbicides (30-39). Application of DLLME for the determination of metal ions in water samples has been used, but the detection technique often used is FAAS, GFAAS, ETAAS, ICP-MS (40-47). Up to date, no report on the combination of atomic fluorescence spectrometry and DLLME for the determination of cadmium has been published.

The goal of the present study is to develop a new method for the sensitive determination of cadmium in water samples making use of the merits of atomic fluorescence spectrometry and DLLME. Important parameters that would affect the extraction efficiency of DLLME and the determination by atomic fluorescence spectrometry were investigated.

\section{EXPERIMENTAL}

\section{Instrumentation}

A Model AF-610B atomic fluorescence spectrophotometer, equipped with a cadmium hollow cathode lamp, was purchased from Beijing Ruili Analytical Instruments Co. Ltd., Beijing, P.R. China. A Model Anke TDL-40B centrifuge (Shanghai Anting Scientific Instruments Factory, Shanghai, P.R. China) was used for accelerating phase separation. The operating parameters of the atomic fluorescence spectrophotometer are listed in Table I.

\section{Reagents}

Stock standard solutions of cadmium with a concentration of $1 \mu \mathrm{g} \mathrm{mL}^{-1}$ were obtained by dissolving appropriate amounts of $\mathrm{CdCl}_{2} \cdot 2.5 \mathrm{H}_{2} \mathrm{O}$ in double-distilled water, purchased from Tianjin Kemiol Chemical Reagent Co. Ltd. (Tianjin, P.R. China). Working standard solutions were obtained by appropriate dilution of the stock

\section{A Amic $_{\text {Soectroscopy }}^{\text {tom }}$}

standard solution. The solution of 8-hydroxyquinoline was prepared by dissolving an appropriate amount of 8-hydroxyquinoline (Beijing Chemical Reagent Factory, Beijing, P.R. China) in ethanol. Double-distilled water was prepared in our laboratory using a quartz-glass vaporizor (Shanghai Ya-rong Biochemistry Instrument Factory, Shanghai, P.R. China). A $27 \%$ concentrated ammonia and $1 \mathrm{~mol} \mathrm{~L}^{-1}$ hydrochloric acid were used for adjusting the sample $\mathrm{pH}$. All glassware used in the experiments was cleaned with pure water, then soaked in $6 \mathrm{~mol} \mathrm{~L}^{-1}$ nitric acid for 24 hours, and washed with ultrapure water.

\section{Dispersive Liquid-Liquid Microextraction}

In the preconcentration procedure, $48 \mathrm{~mL}$ ultrapure water or water sample was added into a 50-mL plastic centrifuge tube. A $100 \mu \mathrm{L}$ amount of $\left(1 \mu \mathrm{g} \mathrm{mL}^{-1}\right)$ cadmium standard solution was spiked into the aqueous solution to provide a spiked concentration of cadmium at $2 \mathrm{ng} \mathrm{mL}^{-1}$. The sample $\mathrm{pH}$ was adjusted to $\mathrm{pH} 9.0$ with $27 \%$ concentrated ammonia. A $100 \mu \mathrm{L}$ amount of $\left(0.001 \mathrm{~mol} \mathrm{~L}^{-1}\right)$ 8-hydroxyquinoline was mixed with the solution and left standing for 10 minutes. A $400 \mu \mathrm{L}$ amount of carbon tetrachloride was dissolved in $1 \mathrm{~mL}$ acetonitrile. This solution was rapidly injected into the aqueous solution with a syringe, then a

\begin{tabular}{|c|c|}
\hline \multicolumn{2}{|c|}{$\begin{array}{c}\text { TABLE I } \\
\text { Instrumetal } \\
\begin{array}{c}\text { Operating Parameters Using } \\
\text { Atomic Fluorescence }\end{array}\end{array}$} \\
\hline Parameters & Values \\
\hline $\begin{array}{l}\text { Negative high } \\
\text { voltage of PMT }\end{array}$ & $270 \mathrm{~V}$ \\
\hline Lamp current & $70 \mathrm{~mA}$ \\
\hline Atomizator height & $7 \mathrm{~mm}$ \\
\hline Argon gas flow rate & $900 \mathrm{~mL} \mathrm{~min}^{-1}$ \\
\hline Injection volume & $1.5 \mathrm{~mL}$ \\
\hline
\end{tabular}


turbid phase immediately formed. Four minutes later, the solution was centrifuged at $4000 \mathrm{rpm}$ for $15 \mathrm{~min}$ utes. The upper aqueous phase was removed with a syringe, and $50 \mu \mathrm{L}$ of a $100 \mu \mathrm{g} \mathrm{mL}^{-1}$ Co solution, $500 \mu \mathrm{L}$ of a $1 \mathrm{~g} \mathrm{~mL}^{-1}$ thiourea solution, and $100 \mu \mathrm{L}$ of concentrated hydrochloric acid were added to the residue of tetrachloride carbon. Then the mixture was vaporized to dryness and the residue dissolved in $5 \mathrm{~mL}$ of $2 \% \mathrm{HCl}$. The final solution was analyzed using the atomic fluorescence spectrophotometer.

\section{Real Water Sample Analysis}

In this experiment, four environmental samples from the exit of the effluent of three factories and a wastewater treatment factory in Xinxiang City, Henan Province, Xinxiang, P.R. China, were used to validate the proposed method. Before use, all of the water samples were filtered through $0.45 \mu \mathrm{m}$ micropore membranes and stored in brown glass containers at $4{ }^{\circ} \mathrm{C}$ temperature.

\section{RESULTS AND DISCUSSION}

DLLME is a new mode of liquid phase microextraction, it is very simple, rapid, and easy to operate. Compared with a conventional liquid phase microextraction, such as single-drop microextraction, DLLME infinitely enlarges the surface area of the extraction solvent and the contact area between the extraction solvent and the analytes, which results in high recoveries of the analytes. Some important factors that affect the preconcentration were investigated in detail.

\section{Effect of Sample pH}

The sample $\mathrm{pH}$ is often an important factor in a DLLME extraction procedure. In general, cadmium ion should be converted into its complex form to make the extraction procedure available. For this goal, the effect of sample $\mathrm{pH}$ was investigated over the $\mathrm{pH}$ range of 1-11 with 8-hydroxyquinoline as chelating reagent; meanwhile, $800 \mu \mathrm{L}$ carbon tetrachloride and $2 \mathrm{~mL}$ methanol were used as the extraction and dispersive solvents for investigating the effect of $\mathrm{pH}$ value, respectively. The extraction and centrifugation times were set as 10 minutes and 20 minutes, respectively. The results in Figure 1 show that the cadmium recoveries increased significantly when the sample $\mathrm{pH}$ increased between the sample $\mathrm{pH}$ range of 1-9 and decreased between the sample $\mathrm{pH}$ range of 9-11. The highest recovery was achieved at $\mathrm{pH} 9$. Thus, the sample $\mathrm{pH}$ was set at $\mathrm{pH} 9$.

\section{Selection of Extraction Solvent and Amount Used}

In the DLLME extraction procedure, the type of extraction solvent and amount used are very important parameters, which significantly influence the extraction efficiency of the analytes. In most cases, the ideal extraction solvent has two properties: one is the hydrophobicity, and the other is high solubility of the analytes. In this study, the organic solvents trichloromethane, carbon tetrachloride, and chlorobenzene were investigated. The experimental results demonstrated that carbon tetrachloride offered the best extraction efficiency for cadmium. It was found that the extraction performance of cadmium was very low with trichloromethane and chlorobenzene. Therefore, carbon tetrachloride was selected for further use. The amount of extraction solvent required is also an importat parameter. In general, the volume of extractant in single-drop microextraction or hollow fiber-based liquid phase microextraction was very small and the enrichment efficiency was very low. In DLLME, the volume of extraction solvent can vary greatly. In this experiment, the volume of carbon tetrachloride was optimized between 200-1000 $\mu \mathrm{L}$

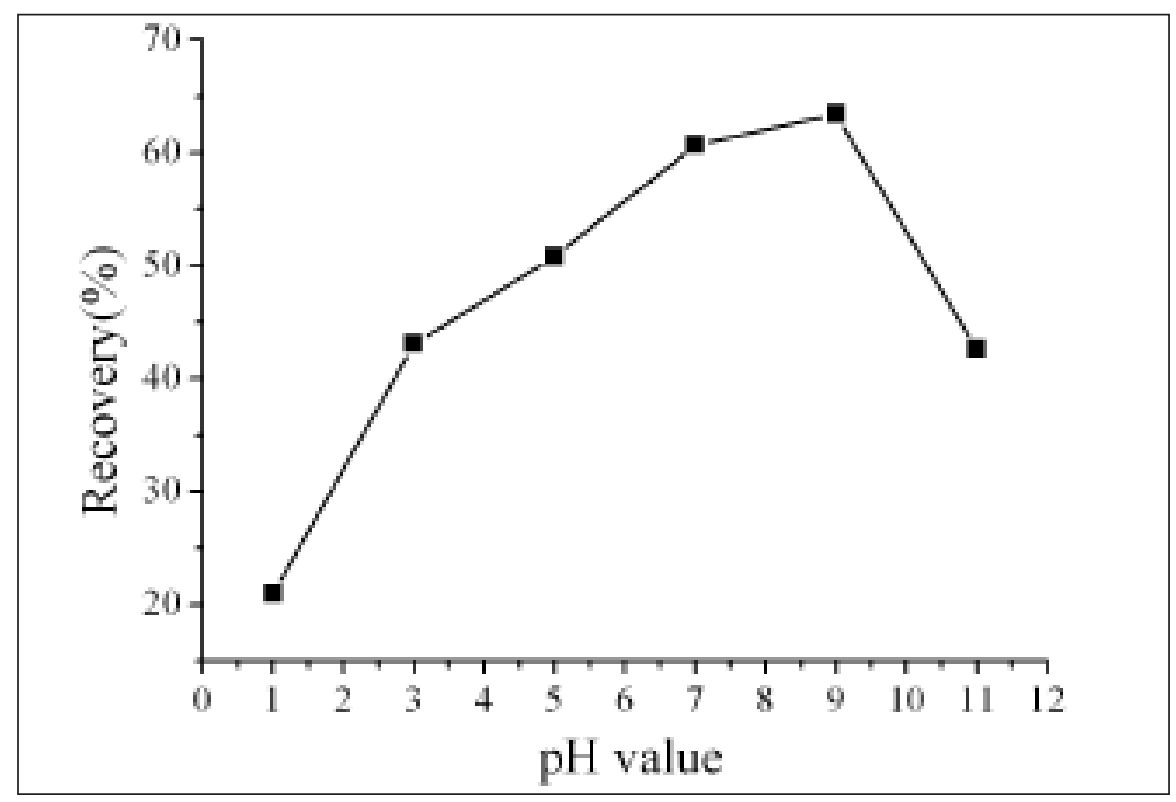

Fig. 1. Effect of sample $p H$. Conditions: extraction solvent, $800 \mu \mathrm{L}$ carbon tetrachloride; dispersive solvent, $2 \mathrm{~mL}$ methanol; extraction time, 10 min; centrifugation time, $20 \mathrm{~min}$ 


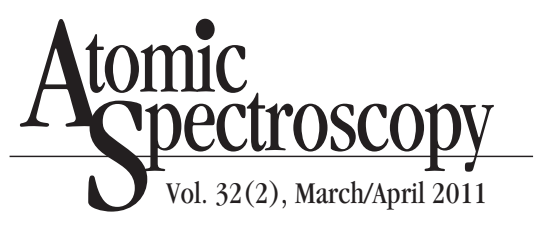

and the results are exhibited in Figure 2 . As can be seen, the recovery of cadmium increased along with an increase in carbon tetrachloride from $200 \mu \mathrm{L}$ to $400 \mu \mathrm{L}$, and then decreased when the volume was further increased. Thus, $400 \mu \mathrm{L}$ carbon tetrachloride was used in subsequent experiments.

\section{Selection of Type and Volume of Dispersive Solvent}

In a DLLME procedure, the type of dispersive solvent and its volume play important roles in the preconcentration of the analytes. In order to select a reasonable dispersive solvent, methanol, ethanol, acetone, and acetonitrile were investigated. The results showed that the lowest enrichment efficiency was achieved when acetone was used. Higher enrichment efficiencies were obtained when ethanol and methanol were utilized as dispersive solvents. The best extraction performance was obtained with acetonitrile which was selected for use in this study. The volume of acetonitrile was also optimized over the range of 200-4000 $\mu \mathrm{L}$ and the results are shown in Figure 3. When the volume of acetonitrile was small, acetonitrile could not disperse carbon tetrachloride completely and a cloudy solution did not completely form. When the volume of acetonitrile was over $1000 \mu \mathrm{L}$, the solubility of the complex in water increased due to an increase in the volume of acetonitrile. Since acetonitrile is misicible with water, an increase in volume would result in the dissolvation of more carbon tetrachloride. Hence, more analytes contained in the dissolved carbon tetrachloride could not be sedimented down, which accounted for the decrease in enrichment performance. Therefore, $1000 \mu \mathrm{L}$ acetonitrile was used in this study.

\section{Effect of Extraction Time}

In this experiment, extraction time was another parameter for DLLME. The effect of extraction time was optimized over 1-25 minutes. The results indicated that the cadmium recoveries were very stable and near 95\% when the extraction time was changed from 1-5 minutes; it decreased significantly when the extraction time was over
5 minutes. Accordingly, 4 minutes was used in further experiments in order to reduce the analytical time.

\section{Effect of Centrifugation Time}

Centrifugation time was also a crucial parameter that affected the separation of carbon tetrachloride from the water phase. The centrifugation time was optimized over the range of 5-25 minutes. The results indicated that the recovery of cadmium increased with an increase in centrifugation time ranging from 5-15 minutes. However, the recovery of cadmium decreased a little when the centrifugation time increased continuously. The longer centrifugation time induced volatilization of carbon tetrachloride; some of the carbon tetrachloride was dissolved in the water phase due to the heat generated from centrifugation, which accounted for the decrease in recovery. For further studies, 15 minutes was selected as the centrifugation time.

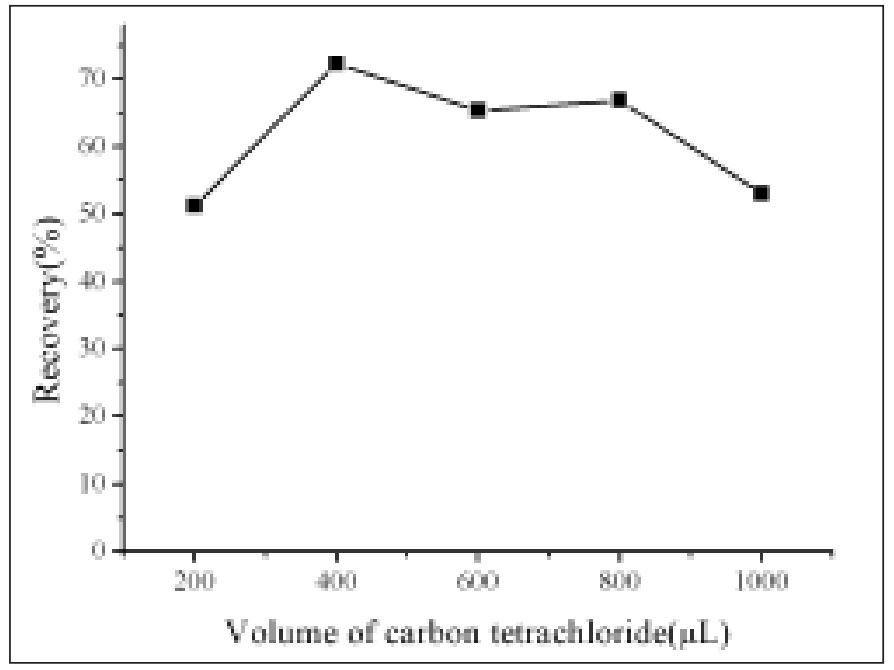

Fig. 2. Effect of volume of carbon tetracbloride. Conditions: dispersive solvent, $2 \mathrm{~mL}$ methanol; sample $\mathrm{pH}$ 9.0; extraction time, 10 min; centrifugation time, 20 min.

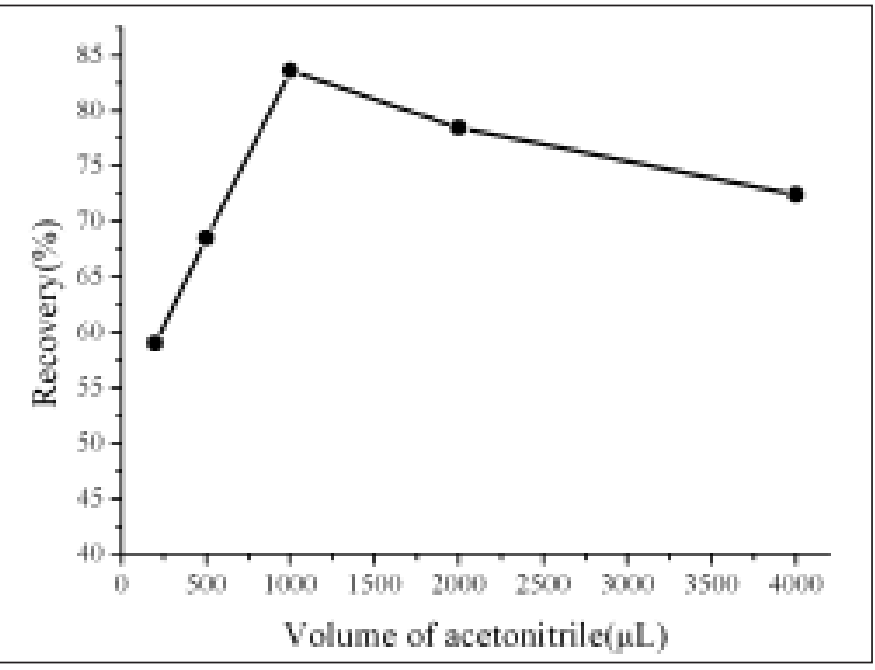

Fig. 3. Effect of the volume of dispersive solvent. Conditions: extraction solvent, $400 \mu \mathrm{L}$ carbon tetrachloride; sample pH 9.0; extraction time, 10 min; centrifugation time, 20 min. 


\section{Effect of Coexisting Ions}

8-hydroxyquinoline is a chelating reagent, which can form stable chelating complexes with many metal ions found in environmental waters and within a wide $\mathrm{pH}$ range. This competitive chelating effect influences the extraction of cadmium. Therefore, the effect of coexisting ions was investigated with a spiked cadmium concentration of $2 \mathrm{ng} \mathrm{mL}-1$ under the aboveoptimized conditions. The results listed in Table II show that the presence of large amounts of cations and anions, including $\mathrm{Na}^{+}, \mathrm{K}^{+}$, and $\mathrm{Ca}^{2}$, had no obvious influence on the recovery of cadmium.

\section{Analytical Performance}

The analytical performance of DLLME coupled with atomic fluorescence spectrometry for the preconcentration and determination of cadmium in environmental samples was investigated under optimal experimental conditions.

The results showed that there was an excellent linear range over $1-40 \mathrm{ng} \mathrm{mL}^{-1}\left(\mathrm{r}^{2}=0.9993\right)$. The precision of this method was $1.93 \%$ (RSD, $\mathrm{n}=7$ ) at the spiked concentra- tion of $2 \mathrm{ng} \mathrm{mL} \mathrm{m}^{-1}$. The detection limit of the proposed method for cadmium (calculated as the concentration corresponding to three times the standard deviation of 17 runs of the blank samples) was $19.4 \mathrm{ng} \mathrm{L}^{-1}$.

\section{Analysis of Real Water Samples}

Four real environmental samples were used to validate the proposed method. Three spiked samples with a concentration of $2 \mathrm{ng} \mathrm{mL} \mathrm{m}^{-1}$ and two blank experiments for each real water sample were carried out according to the abovementioned procedure. The concentration of cadmium in the spiked samples were determined by atomic fluorescence spectrometry and the recoveries were in the range of 81.9-104.0\% (see Table III).

\section{CONCLUSION}

A simple, convenient, robust, and sensitive method is presented for the determination of cadmium in real water samples using dispersive liquid-liquid microextraction (DLLME) and atomic fluorescence spectrometry (AFS). Although the established method seems more

TABLE II

Effect of Coexisting Ions With Spiked Cadmium Concentration of $2 \mathrm{ng} \mathrm{mL}^{-1}$

\begin{tabular}{ccc}
\hline $\begin{array}{c}\text { Coexisting } \\
\text { Ions }\end{array}$ & $\begin{array}{c}\text { Concentration Ratio } \\
\text { of Coexisting } \\
\text { Ions to Cd }\end{array}$ & $\begin{array}{c}\text { Enrichment } \\
\text { Efficiency } \\
(\%)\end{array}$ \\
\hline $\mathrm{Na}^{+}$ & 1000 & 96.95 \\
$\mathrm{~K}^{+}$ & 1000 & 91.78 \\
$\mathrm{Ca}^{2+}$ & 1000 & 92.08 \\
$\mathrm{Cl}^{-}$ & 1000 & 92.08 \\
$\mathrm{Mg}^{2+}$ & 500 & 97.48 \\
$\mathrm{SO}_{4}^{2-}$ & 500 & 97.48 \\
$\mathrm{Al}^{3+}$ & 500 & 91.35 \\
$\mathrm{Zn}^{2+}$ & 100 & 93.49 \\
$\mathrm{Fe}^{3+}$ & 100 & 89.40 \\
$\mathrm{Ni}^{2+}$ & 50 & 101.72 \\
$\mathrm{~Pb}^{2+}$ & 50 & 85.70 \\
$\mathrm{Cu}^{2+}$ & 20 & 91.31 \\
\hline
\end{tabular}




\section{REFERENCES}

1. H. Boiteau and A. Pineau, Cadium, in: H.A. Mc Kenzie and L.E. Smythe (Eds.), Quantitative Trace Analysis of Biological Materials, Elsevier Science Publishers B.V., p. 543 (1988).

2. P. Bermejo-Barrera, A. MoredaPineiro, J. Moreda-Pineiro, and A Bermejo-Barrera, J. Anal. At. Spectrom. 12, 301 (1997).

3. Environmental Protection Agency, EPA, U.S. Federal Register, 440 (c) 5-80-019, (1980)

4. World Health Organization (WHO), Guidelines for DrinkingWater Quality, Health Criteria and Other Supporting Information, Vol. 2, 2nd ed., World Health Organization, Geneva, Switzerland (1998).

5. W.N.L. dos Santos, J. L.O. Costa, R.G.O. Araujo, D. S. de Jesus, and A.C.S. Costa, J. Hazard. Mater. B137, 1357 (2006).

6. S. Mahpishanian and F. Shemirani, Talanta 82, 471(2010).

7. L. Li, B. Hu, L. Xia, and Z. Jiang, Talanta 70, 468 (2006).

8. H.N. Al-Swaidan, Sci. Total Environ. 145, 157 (1994).

9. L.C. Robles and A.J. Aller, Talanta 42, 1731 (1995)

10. Y. Wang and J.H. Wang, Chin. J. Anal. Chem. 34, 1078 (2006).

11. F. Kummrow, F.F. Silva, R. Kuno, A.L. Souza, and P.V. Oliveira, Talanta 75, 246 (2008).

12. J.H. Wang and E.H. Hansen, Anal. Chim. Acta 456, 283 (2002)

13. J.F. Peng, R. Liu, J.F. Liu, B. He, X.L. Hu, and G.B. Jiang, Spectrochim. Acta Part B 62, 499 (2007).

14. Matsumoto, S. Osaki, T. Kobata, B. Hashimoto,H. Uchihara, and T. Nakahara, Microchem. J. 95, 85 (2010).

15. Y. Wang, Z. Liu, G. Yao, P. Zhu, X. Hua, Q. Xu, and C. Yang, Talanta 80, 1959 (2010).

16. R. Wietecha, P. Koscielniak, T. Lech, and T. Kielar, Microchim. Acta 149, 137 (2005).
17. T. Frentiu, M. Ponta, M. Senila, A.I. Mihaltan, E. Darvasi, M. Frentiu, and E.A. Cordos, J. Anal. At. Spectrom. 25, 739 (2010).

18. T. Frentiu, E. Darvasi, M. Senila, M. Ponta, and E. Cordos, Talanta 76 , 1170 (2008).

19. Z. Fang, Flow Injection Atomic Absorption Spectrometry, John Wiley \& Sons, Chichester, U.K. (1995).

20. Z. Fang, Flow Injection Separation and Preconcentration, $\mathrm{VCH}$, Weinheim, Germany (1993).

21. M. Soylak, I. Narin, and M. Dogan, Anal. Lett. 30,2801 (1997).

22. E. Melek, M. Tuzen, and M. Soylak, Anal. Chim. Acta 578, 213 (2006).

23. M. Gawin, J. Konefa, B. Trzewik, S. Walas, A. Tobiasz, H. Mrowiec, and E. Witek, Talanta 80, 1305 (2010).

24. P. Wu, Y. Zhang, Y. Lv, and X. Hou, Spectrochim. Acta Part B 61, 1310 (2006).

25. N. Pourreza and K. Ghanemi, J. Hazard. Mater. 178, 566 (2010)

26. R. Montes, I. Rodríguez, E. Rubí, and R. Cela, J. Chromatogr. A 1216, 205 (2009).

27. H. Farahani, P. Norouzi, R. Dinarvand, and M.R. Ganjali, J. Chromatogr. A 1172, 105 (2007).

28. E. Zhao, W. Zhao, L. Han, S. Jiang, and Z. Zhou, J. Chromatogr. A 1175, 137 (2007).

29. A.P. Birjandi, A. Bidari, F. Rezaei, M.R.M. Hosseini, and Y. Assadi, J. Chromatogr. A 1193, 19 (2008).

30. P. Liang, E. Zhao, and F. Li, Talanta 77, 1854 ( 2009)

31. M.T. Naseri, P. Hemmatkhah, M.R.M. Hosseini, and Y. Assadi, Anal. Chim. Acta 610, 135 (2008).

32. F. Rezaei, A. Bidari, A.P. Birjandi, M.R.M. Hosseini, and Y. Assadi, J. Hazard. Mater. 158, 621 (2008).

33. M. Rezaee, Y. Assadi, M.M. Hosseini, E. Aghaee, F. Ahmadi, and S. Berijani, J. Chromatogr. A 1116, 1 (2006).

34. M. Rezaee, Y. Yamini, S. Shariati, A. Esrafili, and M. Shamsipur, J. Chromatogr. A 1216, 1511 (2009).
35. N. Fattahi, Y. Assadi, M.R.M. Hosseini, and E.Z. Jahromi, J. Chromatogr. A 1157, 23 (2007).

36. L. Fariña, E. Boido, F. Carrau, and E. Dellacassa, J. Chromatogr. A 1157, 46 (2007).

37. Y.Y. Li, G.H. Wei, J. Hu, X.J. Liu, X.N. Zhao, and X.D. Wang, Anal. Chim. Acta 615, 96 (2008).

38. Y. Liu, E. Zhao, W. Zhao, H. Gao, and Z. Zhou, J. Chromatogr. A 1216, 885 (2009).

39. D. Nagaraju and S. D. Huang, J. Chromatogr. A 1161, 89 (2007).

40. E. Z. Jahromi, A. Bidari, Y. Assadi, M.R. M. Hosseini, and M.R. Jamali, Anal. Chim. Acta 585, 305 (2007).

41. S. Mahpishanian and F. Shemirani, Talanta 82, 471 (2010)

42. S.R. Yousefi and F. Shemirani, Anal. Chim. Acta 669, 25 (2010).

43. A.N. Anthemidis, andK.I.G. Ioannou, Anal. Chim. Acta 668, 35 (2010).

44. X. Jia, Y. Han, X. Liu, T. Duan, and H. Chen, Microchim. Acta 171, 49 (2010).

45. A. Moghimi, J. Chin. Chem. Soc. 55,369 (2008).

46. R.E. Rivas, I. López-García, and M. Hernández-Córdoba, Microchim. Acta 166, 355 (2009).

47. E.Z. Jahromi, A. Bidari, Y. Assadi, M.R.M. Hosseini, and M.R. Jamali, Anal. Chim. Acta 585, 305 (2007). 